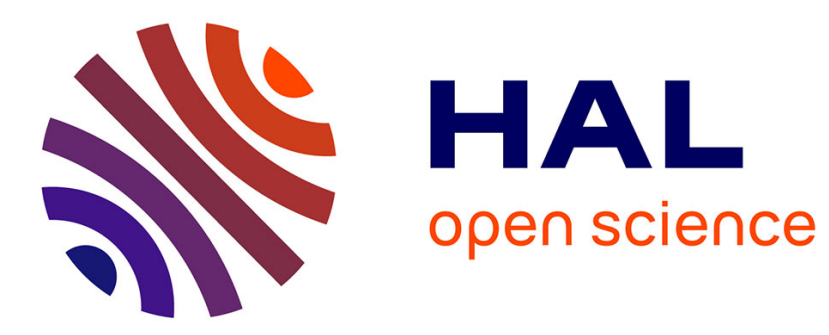

\title{
Acoustical properties of hemp concretes for buildings thermal insulation: Application to clay and lime binders
}

Matthias Degrave-Lemeurs, Philippe Gle, Arthur Hellouin de Menibus

\section{To cite this version:}

Matthias Degrave-Lemeurs, Philippe Gle, Arthur Hellouin de Menibus. Acoustical properties of hemp concretes for buildings thermal insulation: Application to clay and lime binders. Construction and Building Materials, 2018, 160, pp.462-474. 10.1016/j.conbuildmat.2017.11.064 . hal-02915521

\section{HAL Id: hal-02915521 \\ https://hal.science/hal-02915521}

Submitted on 27 May 2021

HAL is a multi-disciplinary open access archive for the deposit and dissemination of scientific research documents, whether they are published or not. The documents may come from teaching and research institutions in France or abroad, or from public or private research centers.
L'archive ouverte pluridisciplinaire HAL, est destinée au dépôt et à la diffusion de documents scientifiques de niveau recherche, publiés ou non, émanant des établissements d'enseignement et de recherche français ou étrangers, des laboratoires publics ou privés. 


\title{
Acoustical properties of hemp concretes for buildings thermal insulation: application to clay and lime binders
}

\author{
Matthias Degrave-Lemeurs ${ }^{\mathrm{a}, \mathrm{b}}$, Philippe Glée, \\ Arthur Hellouin de Menibus ${ }^{\mathrm{b}, \mathrm{c}, * *}$ \\ ${ }^{a}$ Cerema Est, 11 rue Jean Mentelin, 67035 Strasbourg, France \\ ${ }^{b}$ Eco-Pertica, Hôtel Buissonnet, 61340 Perche-en-Nocé, France \\ ${ }^{c}$ French National Association of Short Distribution Network Hemp Producers (Association \\ Nationale des Chanvriers en Circuits Courts), Hôtel Buissonnet, 61340 Perche-en-Nocé, \\ France
}

\begin{abstract}
This experimental and modelling study provides a general overview of the acoustical performance of hemp-lime and hemp-clay for building thermal insulation at the material scale. It is based on statistically robust experimental results from more than 100 hemp-clay samples, together with the analysis of a large hemp-lime database.

In hemp-clay mixes, our experimental results show the concentration of hemp in a mix has a first order effect on the acoustical performance, while binder fluidity and clay type have no effect. Another conclusion of this study is that hemp-clay and hemp-lime behave acoustically in a similar way. For both materials, experimental sound absorption and transmission curves can be modelled with a physical-based four-parameters approach. The close agreement between experimental measurements and modelling highlights the good level of understanding of the physical phenomena responsible for the acoustical behavior of hemp concrete.

A classification is finally proposed in terms of density to be used as a general guideline to evaluate or optimize the acoustical performances of hemp-based concrete.
\end{abstract}

\footnotetext{
*Corresponding author: philippe.gle@cerema.com

${ }^{* *}$ Corresponding author: arthur.hdm@ecopertica.com
} 
Keywords: Eco-construction, acoustical properties, thermal insulation, clay, lime, hemp

\section{Introduction}

The use of bio-based materials for thermal insulation is a solution for reducing environmental impacts of the building sector, which represents $40 \%$ of the worldwide energy use [1, 2].

5

Different bio-based materials have different environmental impacts. For instance, most actual bio-based thermal insulation panels include about $15 \%$ of polyester in mass to tighten the fibres together. In hemp wool panels, this small amount of polyester has an environmental impact 7 to 8 times higher than the hemp wool production itself (in $\mathrm{kg}_{\text {eq. }} \mathrm{CO} 2$ ) [3]. In addition, due to this low amount of polyester, the end of life strategy of the panel cannot be a composting like the bioresource alone. Alike conventional thermal insulation material (glass wool...), its end of life requires the organization of a recycling branch for collecting and processing operations. A raw bio-based material resulting from a simple and low energy demanding transformation process often has an addi15 tional benefit: it does not need a highly industrialized and costly plant to be produced. Thus, the economic balance point can be reached while maintaining production and commercialization at a local scale (leq $100 \mathrm{~km})$. This is the case of light earth.

Light earth is unfired clay lightened with renewable particles in order to improve the thermal insulation. Earths that are well-suited for construction often have a natural dry density about 1500 to $1800 \mathrm{~kg} . \mathrm{m}^{-3}$. Figure 1 shows some light earth construction techniques depending on the targeted dry density. Light earth above $1000 \mathrm{~kg} \cdot \mathrm{m}^{-3}$, such as straw-clay blocks, is heavy and has poor thermal insulation properties (thermal conductivity $\lambda$ above $0.2 \mathrm{~W} \cdot \mathrm{m}^{-1} \cdot \mathrm{K}^{-1}$ at $10^{\circ} \mathrm{C}$ dry state). The particles are often fibres whose main role is to prevent drying cracks. Light earth between 500 and $1000 \mathrm{~kg} \cdot \mathrm{m}^{-3}$ is not light enough to be considered as an efficient thermal insulator, with $\lambda$ within the range 0.1 
to $0.2 \mathrm{~W} \cdot \mathrm{m}^{-1} \cdot \mathrm{K}^{-1}$ at $10^{\circ} \mathrm{C}$ dry state. A "hemp-lime or hemp-clay thermal corrector plaster" (a $6 \mathrm{~cm}$ light plaster applied with a trowel on an existing wall to reduce the "cold wall" effect) has a density included in this range, generally between 700 and $900 \mathrm{~kg} \cdot \mathrm{m}^{-3}$. Below $500 \mathrm{~kg} \cdot \mathrm{m}^{-3}$, light earth might be considered as an option for insulation purposes but the density has to be reduced to 300 - $400 \mathrm{~kg} \cdot \mathrm{m}^{-3}$ to reach the thermal insulation material threshold $\lambda \leq 0.065$ $\mathrm{W} \cdot \mathrm{m}^{-1} \cdot \mathrm{K}^{-1}$ (at $10^{\circ} \mathrm{C}$ at dry state) defined in the standard NF P75-101 [4. 35 Light earth between 200 and $500 \mathrm{~kg} \cdot \mathrm{m}^{-3}$ can be used for building works by shuttering techniques, spraying or casted blocks, with or without a timber frame. Light earth with density lower than $200 \mathrm{~kg} . \mathrm{m}^{-3}$ has a low mechanical resistance, but it can be used as a filling material in lost casing. The lowest density bound is the aggregate one, about $100 \mathrm{~kg} \cdot \mathrm{m}^{-3}$ for hemp shiv.

40 Light earth properties and applications for building thermal insulation were first studied by German research teams. Some of their results were published in a high quality compilation [5]. Different light earth mixes were recently studied by different research teams, mostly focusing on thermal and hygrothermal properties, using straw [6], coco [7, typha [8, hemp [9], rape straw and sunflower 45 10. A raw comparison between hemp-clay [9, 11] and hemp-lime [12, 13, 14] shows these mixes have rather similar thermal and hygrothermal performances, but hemp-clay has a 20 times lower embodied energy.

Using clay over lime or cement has several advantages (environmental impact, economic...). Clayed earth can be found easily on a local scale : it is a widespread material in the sub-ground, and it is often available in large quantities after public works for free on a economical and environmental standpoint. The main difference between theses binders is that the setting of clay is a reservible process because only due to drying, while the setting of lime and cement is an irreversible process. The benefit is that unstabilized clay based concrete 55 is infinitely repairable and recyclable. The drawback of the reversible setting of the clay is that, in contact to a large quantity of liquid water, clay will become mud again. Nevertheless, all insulation materials, even glass wool, suffer from liquid water which induces either compaction or degradation. The durability 


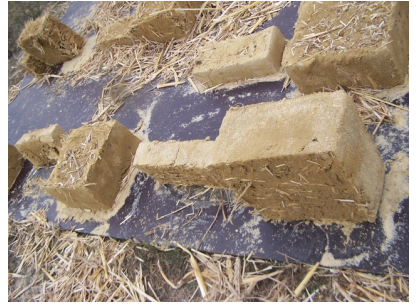

(a) Brick with fibres (1 200 kg.m $\left.{ }^{-3}\right)$

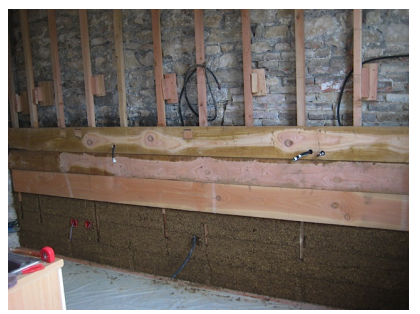

(c) Shuttering $\left(200-500 \mathrm{~kg} \cdot \mathrm{m}^{-3}\right)$.

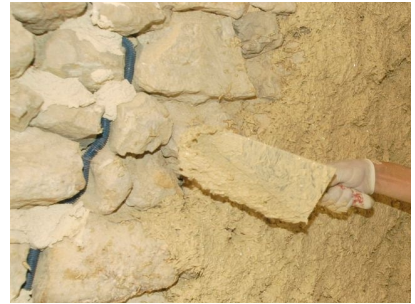

(b) Coating with a trowel (800 $\left.900 \mathrm{~kg} \cdot \mathrm{m}^{-3}\right)$.

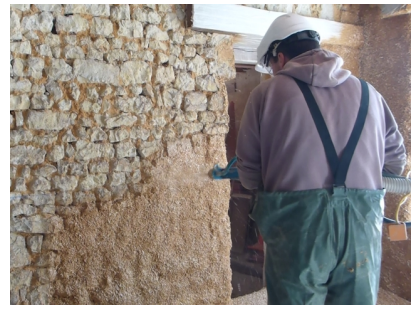

(d) Spraying $\left(200-500 \mathrm{~kg} \cdot \mathrm{m}^{-3}\right)$.

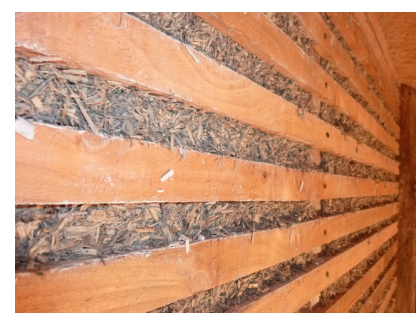

(e) Lost-casing $\left(\leq 200 \mathrm{~kg} \cdot \mathrm{m}^{-3}\right)$.

Figure 1: Different construction methods associated to hemp-lime or hemp-clay density. Some pictures courtesy of Vincent Corbard.

of a clay concrete insulation is similar to the one of traditional houses made of stones, wood and clay : it can last for several centuries, up to the point where the building is heavily exposed to liquid water (often due to a degraded roof).

Acoustical properties are usually described by two quantities, the sound absorption coefficient $\alpha$ and the transmission loss $T L$, the latter corresponding to the sound insulation. These performances can be characterized at three 65 scales : building, wall and material scale. The methods for measurements in 
buildings are described in standards [15]. However, a scientific interpretation of these on-site results is generally complex. To control more precisely the boundary conditions, experiments can be performed in laboratory at the wall scale under diffuse field conditions. These measurements are done in anechoic chambers for $\alpha$ [16] and between two reverberant rooms for $T L$ [17]. On the one hand, these methods can be quite representative of building techniques, including for instance a timber frame or a rendering plaster for light earth construction. On the other hand, it is often difficult to directly correlate the global acoustic performance of the wall with the individual material acoustical contributions. In addition, these tests are expensive and time-consuming due to the large amount of material needed. Thus, tests can be performed in laboratory at the material scale, with the use of impedance tubes with incidence of normal plane waves. A number of methods have been developed in this context to characterize both sound absorption and transmission loss [18, 19, 20].

80

Sound dissipation in porous media has also been extensively studied in the literature [21]. For hemp-based concretes, the approach is made complex by the existence of multiple pores scales respectively in the binder, in the aggregates and between the aggregates. The materials are studied acoustically at the dry state as end materials, and not just after fabrication at a water-saturated state, 85 which explains this significant porosity. The acoustical properties are principally ruled by the interparticle pores scale [22], given the fact that intrabinder and intraparticle pores are masked due to a double porosity high contrast of permeability effect [23]. This fact allowed other studies to use an acoustical approach to characterize aggregates such as hemp, flax, sunflower and rape particles microstructure [24, 25].

To our knowledge there is no literature concerning acoustical properties of light earth. However, several studies dealt with the sound properties of hemplime. The effect of the manufacturing process has been explored in [26], showing that a large range of properties can be reached with this material by using 95 various binder content and binder type. The particle size distribution of the aggregates has a significant incidence on acoustical properties of loose particles 
[26, 24, 27], but is however partly hidden in hemp-lime due to a predominant effect of the binder.

Differences between hemp-lime and hemp-clay mixes could exist due to the

\section{Materials and Methods}

\subsection{Materials}

\subsubsection{Constituents}

Two different earths with clay were used, both collected from earthworks 
cohesive" and without gravels, and were considered well adapted for light earth by a specialized craftsman. No additive or stabilization technics were used. Clays were characterized to obtain their granulometry and clays activity (blue methylene test [29]). The blue methylene test is based on the replacement of the cations of clays by methylene blue dye. This test consists of the following steps :

- Separation of the clay fraction of the earth by sieving,

- Mixing of clay and a large quantity of water,

- Progressive incorporation of blue methylene up to the point were the clay solution is saturated.

This test gives a blue methylene value at saturation which is a function of the amount and characteristics of clay minerals present in the test specimen. This value is correlated to the weighted clay activity, that relates the plasticity of a clay to the percentage of clay size particles present in a sample.

Interestingly, both clays have similar methylene blue values (Table 1). Clay 2 (gray) has a low fraction (6\%) of very active clay, while clay 1 (red) has a high fraction $(37 \%)$ of normally active clay. The fraction of gravel is low for both clays. They have a similar amount of sand (about 40\%), but a different amount of silt that compensate the clay fraction. The complete granulometry is shown on the Figure 2 (left).

These clays were mixed with water to obtain sludges. These sludges were sieved with a $1.85 \mathrm{~mm}$ mesh size before being used with hemp as binders. Two moulds were filled with these binders and their contents were dried and their dimensions and weight were measured to calculate the density of dry binders 150 (Table 2 ).

The shiv used was produced in Normandy. The variety is FEDORA 17, sowed at $50 \mathrm{~kg} / \mathrm{ha}$, harvested in autumn and defibered in a local producer transformation unit (Eco-Pertica). Shiv granulometry was characterized as follows : particles were carefully arranged on a high resolution scanner, and were 


\begin{tabular}{l|c|c}
\hline Reference & Clay 1 & Clay 2 \\
\hline Color & Red & Gray \\
Clay (\%) $(0-2 \mu \mathrm{m})$ & 37 & 6 \\
Silt $(\%)(2-50 \mu \mathrm{m})$ & 17 & 44 \\
Sands (\%) $(50 \mu \mathrm{m}-2 \mathrm{~mm})$ & 37 & 42 \\
Gravel (\%) $>2 \mathrm{~mm})$ & 9 & 8 \\
Maximal diameter $(\mathrm{mm})$ & 20 & 20 \\
Blue Methylene value & 2.47 & 2.20 \\
Clay Activity & 7 - Normal & $35-$ Harmful \\
\hline
\end{tabular}

Table 1: Granulometry and activity of clays.

\begin{tabular}{c|c}
\hline Dry binder & Density $\left(\mathrm{kg} \cdot \mathrm{m}^{-3}\right)$ \\
\hline 1 & $1818 \pm 132$ \\
2 & $1586 \pm 97$ \\
\hline
\end{tabular}

Table 2: Density of dry binders made from two clays. done using image J software (binarization - separation in black and white - fit of the particle shape). It gave access to the distributions of the width and length of particles, which follows log-normal functions (Equation 1). The log-normal parameters identified on more than 800 particles are given in Table 3 and results

$$
P=\frac{1}{2}\left(1+\operatorname{erf}\left(\frac{\ln (x)-\mu}{\sigma \sqrt{2}}\right)\right)
$$

where $x, \mu$ and $\sigma$ are the mesh-size and the log-normal parameters.

Dust ratio is low: $0.3 \%$ in mass. The density measured following the RILEM procedure 30 is $90.9 \mathrm{~kg} \cdot \mathrm{m}^{-3}$. Fibre content is $3.9 \%$ in mass, and fibres are short, smaller than $2-4 \mathrm{~cm}$. 


\begin{tabular}{c|cc} 
& $\mu$ & $\sigma$ \\
\hline Width & 0.33 & 0.49 \\
Length & 1.94 & 0.48
\end{tabular}

Table 3: Parameters for log-normal approximation of width and length distributions of the shiv
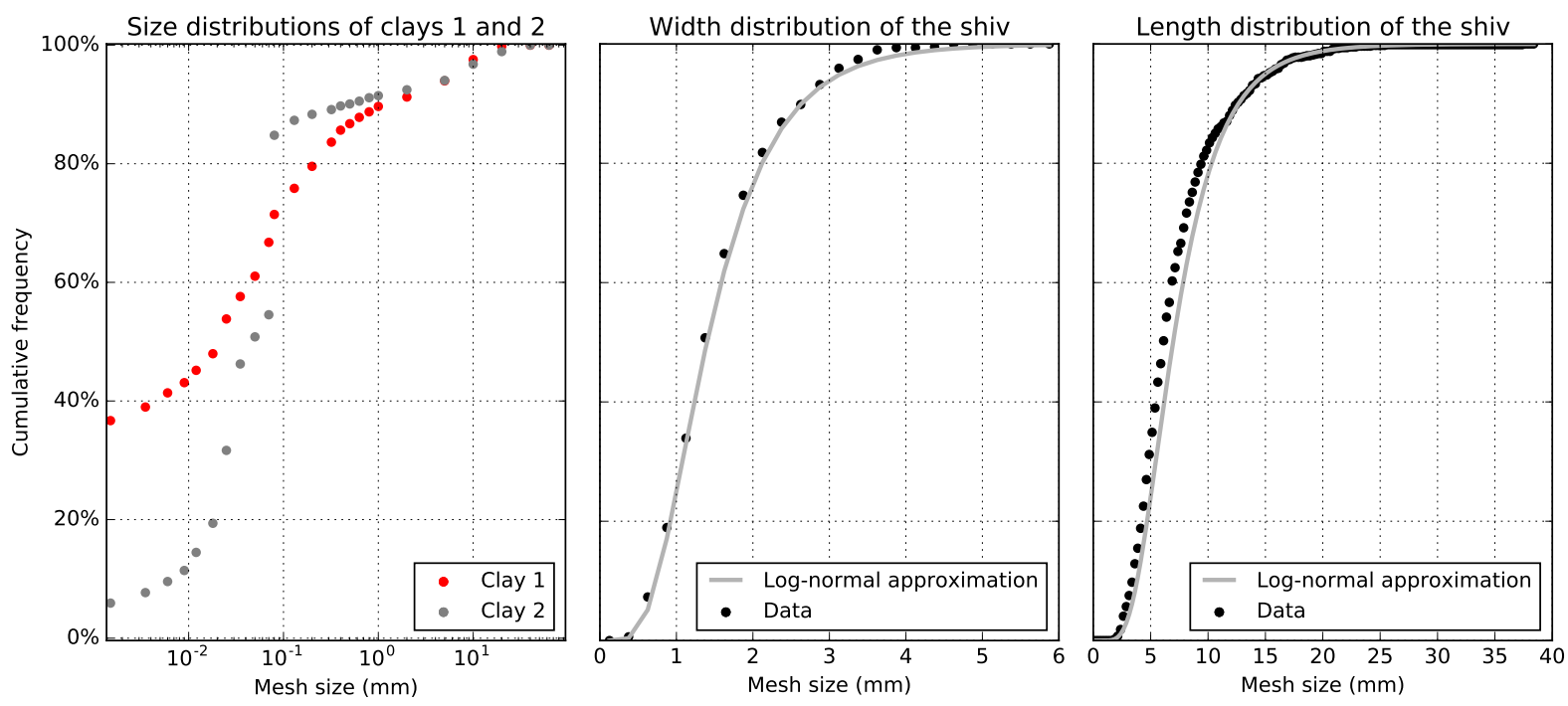

Figure 2: Left: clays granulometry (points were linked with a line for readability purposes). Center and right: cumulative distributions for width and length of shiv particles (measurement and log-normal approximation). 
Several hemp-clay mixes were prepared as described in Table 6, using a conventional works sector mixer. Water to clay ratio was adjusted to obtain three viscosity levels, noted here "Very Fluid" (VF), "Fluid" (F) and "Viscous" $(\mathrm{V})$. All three of these viscosities were considered acceptable for light earth construction. Viscosity was controlled with a modified flow cup method, which consists in diving a funnel into the sludge, pulling it out, waiting until the sludge flow becomes jerky and weighting the funnel coated with sludge. This test is representative of the common test used by specialized craftsman to check the sludge consistency for light earth construction, the so called "glove test". The craftsman dives and pull back his hand into the mix, and check if the sludge make a perfect glove around his hand (not too thick, not too thin). To obtain a similar viscosity level, less water was required with clay $2($ activity $=2,2)$ than with clay 1 (activity $=2,47$ ).

\begin{tabular}{c|c|c}
\hline Viscosity & Clay 1 & Clay 2 \\
\hline Very Fluid & 1.75 & 1.70 \\
Fluid & 1.52 & - \\
Viscous & 1.28 & 0.88 \\
\hline
\end{tabular}

Table 4: Water to clay mass ratios depending on the clay (these ratios include the water initially present in the clay).

The hemp/binder mass ratio was set up to $30 \%$. It means most mixes were made out from $3 \mathrm{~kg}$ of hemp for $10 \mathrm{~kg}$ of binder. Two mixes were prepared with a hemp/binder mass ratio of 25 and $40 \%$ to study the effect of this parameter. Three levels of compaction ("Low", "Intermediate" and "High") were defined in order to quantify the effect of a variation of the density of samples having the same composition. For repeatability purposes, the compaction level was controlled by measuring the mass of wet hemp-clay mix required to fill moulds having the same volume. Densities aimed after compaction of the wet material are given in Table 5 with the ranges of density obtained for the corresponding 
dry samples. Six samples were prepared for each mix, for a total of 102 samples. The dry density standard deviation for a given formulation was about 1.7 to 8.8 kg. $\mathrm{m}^{-} 3$. It is about $2 \%$ on average in the explored dry density range.

\begin{tabular}{c|c|c}
\hline $\begin{array}{c}\text { Compaction } \\
\text { level }\end{array}$ & $\begin{array}{c}\text { Wet density } \\
\text { after compaction }\left(\mathrm{kg} \cdot \mathrm{m}^{-3}\right)\end{array}$ & $\begin{array}{c}\text { Dry density range } \\
\left(\mathrm{kg} \cdot \mathrm{m}^{-3}\right)\end{array}$ \\
\hline Low & 383.1 & {$[192.4,226.5]$} \\
Intermediate & 504.5 & {$[243.4,295.8]$} \\
High & 625.8 & {$[285.7,347.7]$} \\
\hline
\end{tabular}

Table 5: Control of the compaction level. The variability in the dry density range obtained is due to different amount of water in the binder depending on the clay used and the viscosity level aimed.

Measurements were performed at dry state : samples were dried in an oven at $50^{\circ} \mathrm{C}$ until their masses got stabilized (daily variation lower than $0.1 \%$ over $72 \mathrm{~h}$ ). The impact of water content on the acoustical properties of hemp shiv and hemplime is limited [22]. This parameter was thus considered as a modest priority compared to hemp concentration, compaction, type of clay or the viscosity of the binder.

\subsection{Characterization methods}

\subsubsection{Acoustical properties}

Assuming a rigid frame, two frequency-dependent properties fully describe the acoustical behavior of a porous material: the equivalent dynamic density $\rho$ and the dynamic incompressibility modulus $K$ (usually reduced to bulk modulus). These properties are intrisic in the sense that they are not related to the thickness. They respectively reflect the visco-inertial (viscous friction of the fluid at the pore-frame interface) and thermal (heat exchanges between pores and frame) dissipation effects in the pores.

A harmonic time dependence of type $\exp ^{j \omega t}$ is considered in this paper, with $\omega=2 \pi f$ the pulsation, $f$ the frequency and $j^{2}=-1$. Knowing the couple $(\rho, K)$ and the thickness $e$ of a sample, it is possible to compute the sound absorption 


\begin{tabular}{|c|c|c|c|c|c|}
\hline Clay & $\begin{array}{l}\text { Binder } \\
\text { viscosity }\end{array}$ & $\begin{array}{c}\text { Hemp/Binder } \\
\text { mass ratio }\end{array}$ & $\begin{array}{c}\text { Compaction } \\
\text { level }\end{array}$ & Code & $\begin{array}{c}\text { Average dry } \\
\text { density }\left(\mathrm{kg} \cdot \mathrm{m}^{-3}\right)\end{array}$ \\
\hline \multirow{2}{*}{1} & \multirow{2}{*}{ Viscous $(V)$} & 0.25 & \multirow{2}{*}{ Intermediate } & $1 \_V \_0.25 \_$Inter & $292.6 \pm 4.4$ \\
\hline & & 0.4 & & $1 \_V \_0.4 \_$Inter & $269.5 \pm 3.8$ \\
\hline \multirow{9}{*}{1} & \multirow{3}{*}{ Very Fluid $(V F)$} & \multirow{9}{*}{0.3} & Low & 1_VF_0.3_Low & $195.8 \pm 3.4$ \\
\hline & & & Intermediate & 1_VF_0.3_Inter & $243.4 \pm 4.1$ \\
\hline & & & High & 1_VF_0.3_High & $285.7 \pm 2.7$ \\
\hline & & & Low & 1_F_0.3_Low & $215.7 \pm 6.3$ \\
\hline & Fluid $(F)$ & & Intermediate & $1_{-} F_{-} 0.3 \_$Inter & $264.7 \pm 8.8$ \\
\hline & \multirow{4}{*}{ Viscous $(V)$} & & High & 1_F_0.3_High & $308.9 \pm 2.9$ \\
\hline & & & Low & 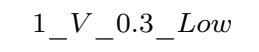 & $223.7 \pm 8.0$ \\
\hline & & & Intermediate & 1_V_0.3_Inter & $280.9 \pm 8.2$ \\
\hline & & & High & 1_V_0.3_High & $328.8 \pm 1.7$ \\
\hline \multirow{6}{*}{2} & \multirow{4}{*}{ Very Fluid $(V F)$} & \multirow{6}{*}{0.3} & Low & 2_VF_0.3_Low & $209.4 \pm 2.1$ \\
\hline & & & Intermediate & $2 \_V F \_0.3 \_$Inter & $258.5 \pm 3.9$ \\
\hline & & & High & 2_VF_0.3_High & $309.2 \pm 6.2$ \\
\hline & & & Low & $2{ }^{2}{ }_{-} 0.3 \_$Low & $233.3 \pm 5.9$ \\
\hline & \multirow[t]{2}{*}{ Viscous $(V)$} & & Intermediate & $2{ }_{-}{ }_{-} 0.3 \_$Inter & $295.8 \pm 4.6$ \\
\hline & & & High & $2 \_V \_0.3 \_H i g h$ & $347.7 \pm 8.1$ \\
\hline
\end{tabular}

Table 6: Characteristics (composition and compaction level) of hemp-clay mixes. 
coefficient $\alpha$ and sound transmission loss $T L$ in normal incidence (Equations 2 material, having a limp or rigid behavior 20.

$$
\alpha=1-\left|\frac{Z s-Z_{0}}{Z s+Z_{0}}\right|^{2}
$$

where $Z_{0}$ is the acoustical impedance of air, and $Z s$ the acoustical surface impedance, equal to:

$$
\begin{gathered}
Z s=-j \sqrt{\rho K} \cot \left(\omega \sqrt{\frac{\rho}{K}} e\right) \\
T L=-10 \log _{10}\left(\left|\frac{2 \exp ^{j k_{0} e}}{2 \cos \left(\omega \sqrt{\frac{\rho}{K}} e\right)+j \sin \left(\omega \sqrt{\frac{\rho}{K}} e\right)\left(\frac{\sqrt{\rho K}}{Z_{0}}+\frac{Z_{0}}{\sqrt{\rho K}}\right)}\right|^{2}\right)
\end{gathered}
$$

A number of acoustical models of the literature could be used to evaluate $\rho$ and $K[21,31,32,33,34,35,36$. These models require between one and more than eight parameters depending on the complexity of the porous microstructure being considered. Indirect characterization strategies consist in using these models to estimate some of their parameters from the measurement of $\rho$ and $K$. Many of theses strategies start from the knowledge of the acoustical porosity $\phi_{a c}$ (porosity acoustically active, see Section 3.1). A specificity of hemp shiv or hemp-based concretes is that this key parameter cannot be directly measured but only deduced from acoustical measurement of $K$ and the number of relevant models is consequently limited. For such materials, an approach combining Zwikker \& Kosten and Johnson et al models [33, 34] is well-suited

225 [24, 27]. Visco-interial effects are described by Johnson et al model [33, while thermal dissipation is based on the cylindrical Zwikker \& Kosten model [34]. This combination can be qualified as hybrid since an identical pore model, based on a circular pore geometry, is considered for thermal effects but not for viscoinertial ones. The idea of this combination is to avoid the introduction of a fifth 
the material), since acoustical porosity cannot be directly measured. This modelling approach is presented and validated in more details for hemp shiv in [24, 27. The equations of these models are given below:

$$
\begin{array}{r}
\rho=\frac{\mu_{0} \alpha_{\infty}}{\phi_{a c}}\left[1-j \frac{\sigma \phi_{a c}}{\mu_{0} \alpha_{\infty} \omega} \sqrt{1+j \frac{4 \eta \alpha_{\infty}^{2} \mu_{0} \omega}{\Lambda^{2} \sigma^{2} \phi_{a c}^{2}}}\right] \\
K=\frac{\gamma P_{0}}{\phi_{a c}}\left[1+\frac{2(\gamma-1)}{\sqrt{N_{P r}} u \sqrt{-j}} \frac{J_{1}\left(\sqrt{N_{P r}} u \sqrt{-j}\right)}{J_{0}\left(\sqrt{N_{P r}} u \sqrt{-j}\right)}\right]^{-1}
\end{array}
$$

Where $u=\sqrt{\frac{8 \omega \mu_{0} \alpha_{\infty}}{\sigma \phi_{a c}}}, J_{0}$ and $J_{1}$ are Bessel functions of respective orders 0 and $1, \mu_{0}$ is the density of air, $\eta$ is its viscosity, $\gamma$ the ratio of its specific heats and $N_{P r}$ its Prandtl number.

In total, this model counts four parameters, estimated from the measured dynamic density $\rho$ and bulk modulus $K$ using the methodology presented in [24] and principally based on Olny and Panneton methods [37, 38]:

- the air flow resistivity $\sigma$ (static resistance of the material to air flow, given in N.s.m ${ }^{-4}$,

- the tortuosity $\alpha_{\infty}$ (sinuosity of the porous path),

- the acoustical porosity $\phi_{a c}$ (porosity acoustically active, see Section 3.1),

- the characteristic viscous length $\Lambda$ (characteristic size of the interconnexion between pores, given in $\mathrm{m}$ ).

All acoustical measurements were performed using a $100 \mathrm{~mm}$ diameter and $1.45 \mathrm{~m}$ length Kundt tube (impedance tube in which propagate plane waves for a given frequency range), equipped with three microphones and a speaker. This source generates a white noise, covering a spectrum between 50 and over $10000 \mathrm{~Hz}$. However, the standard ISO 10534-2 [18] defines a lower and an upper frequency. The upper frequency depends on the lateral size (here the diameter) of the tube and working under this frequency is a condition for having plane waves propagating in the tube. The existence of the lower frequency is imposed 
by a signal processing issue and its value depends on the distance between the two first microphones. Here these frequencies are respectively 250 and $2000 \mathrm{~Hz}$.

The choice of the sample face in the Kundt tube could affect the results if the binder was able to migrate in the sample during its drying [26]. In this case, both faces would not share the same aspect and would have different levels of porosity resulting in different acoustical behaviors. In a preliminary study, we performed some tests on one face and then on the other face, but no significant difference was observed. As a consequence, all the samples were studied only with one face.

The model proposed by Johnson et al. [33] shows that the asymptotic behavior of imaginary part of the dynamic density in the low frequencies is directly linked to the resistivity.

$$
\sigma=\lim _{\omega \rightarrow 0}(-\omega \Im(\rho))
$$

The ratio $\frac{\alpha_{\infty}}{\phi_{a c}}$ as well as the viscous length $\Lambda$ were calculated using the real and the imaginary parts of the dynamic density using an inverse analytical procedure described in [38]. Zwikker-Kosten model was then used to predict the real part of bulk-modulus [34]. The acoustical porosity $\phi_{a c}$ was deduced from the minimization of the discrepancy between this prediction and the measurement of $K$. Knowing the ratio $\frac{\alpha_{\infty}}{\phi_{a c}}$ and the acoustical porosity $\phi_{a c}$, the tortuosity $\alpha_{\infty}$ was finally calculated.

\subsubsection{Static air flow resistivity}

The static air flow resistivity of samples was also directly measured for all samples following the standard procedure described in the standard ISO 9053 [39, using a static air flow resistivity meter.

\subsubsection{Open porosity}

The density of the frame was determined on the base of three measurements for the different constituents (shiv and dry binder) and every mixes (three parts 280 of one sample were used per mix), even though the frame density theoretically 
depends only on the composition of the mix and not on its compaction. Knowing the density $\mu$ of a material and its frame density $\mu_{\text {frame }}$, it is possible to calculate its open porosity $\phi_{\text {open }}$ :

$$
\phi_{\text {open }}=1-\frac{\mu}{\mu_{\text {frame }}}
$$

These measurements were performed using an air porosimeter and the method

285 enable a comparison between the open and acoustical porosities of hemp-clay.

\section{Experimental results}

\subsection{Open porosity}

The results of the air porosimetry characterization of the constituents is

290 and $\left.2600 \mathrm{~kg} \cdot \mathrm{m}^{-3}[22]\right)$.

\begin{tabular}{ccc}
\hline Component & Frame dry density $\left(\mathrm{kg} \cdot \mathrm{m}^{-3}\right)$ & Open porosity (\%) \\
\hline Shiv & $1102 \pm 44$ & $91.7 \pm 1.2$ \\
Binder 1 & $3198 \pm 56$ & $43.2 \pm 5.2$ \\
Binder 2 & $2945 \pm 47$ & $41.9 \pm 4.2$ \\
\hline
\end{tabular}

Table 7: Frame density of constituents.

The experimental range of variations in the frame density of hemp-clay mixes is 1788 to $2128 \mathrm{~kg} \cdot \mathrm{m}^{-3}$ (Table 8). There is no direct correlation between the frame dry density and the clay type, clay viscosity or compression level. 


\begin{tabular}{|c|c|c|c|}
\hline \multirow{2}{*}{ Composition } & \multicolumn{3}{|c|}{ Frame density $\left(\mathrm{kg} \cdot \mathrm{m}^{-3}\right)$} \\
\hline & Low comp. & Inter. comp. & High comp. \\
\hline $1_{-} V_{-} 0.25$ & - & $2128 \pm 87$ & - \\
\hline $1{ }_{-} V_{-} 0.3$ & $1846 \pm 74$ & $1866 \pm 69$ & $1997 \pm 77$ \\
\hline $1_{-} V \_0.4$ & - & $1788 \pm 79$ & - \\
\hline $1_{-} F_{-} 0.3$ & $2028 \pm 88$ & $1994 \pm 84$ & $2006 \pm 87$ \\
\hline $1{ }_{-} V F{ }_{-} 0.3$ & $1901 \pm 86$ & $1990 \pm 91$ & $1950 \pm 83$ \\
\hline $2 \_V \_0.3$ & $1843 \pm 70$ & $1832 \pm 71$ & $1846 \pm 76$ \\
\hline $2 \_V F \_0.3$ & $1888 \pm 71$ & $1892 \pm 79$ & $1870 \pm 72$ \\
\hline
\end{tabular}

Table 8: Frame density of mixes.

The variation ranges of the open porosity are respectively 87.3 to $89.7 \%$, 83.9 to $87.8 \%$ and 81.2 to $85.3 \%$ for low, intermediate and high compaction levels.

\subsection{Static air flow resistance}

Figure 3 gives the resistivity obtained with both acoustical and direct methods for three mixes (6 samples each). A similar comparison gave similar results in [22]. Our results shows both technics give similar result for heavy samples $\left(>300 \mathrm{~kg} / \mathrm{m}^{3}\right)$, but indirect measurements overstimate the resistivity for lower density samples. The trends from one sample to another one are similar for both technics, which shows the bias at low density is not due to uncertainties. The indirect method based on Kundt tube measurements is known for giving very good estimates of $\sigma$ if the characterization is performed below the viscous characteristic frequency $f_{v}=\frac{1}{2 \pi} \frac{\sigma \phi_{a c}}{\mu_{0} \alpha_{\infty}}$. However, this frequency $f_{v}$ is lower for light samples (due to lower resistivities), so that $\sigma$ cannot be estimated in a pure viscous dissipation frequency domain in this case.

Thus, our analyses were done using the resistivity coming from the direct measurements. However, we checked what would have been the results if the resistivity from the Kundt tube measurements analysis were used to estimate 


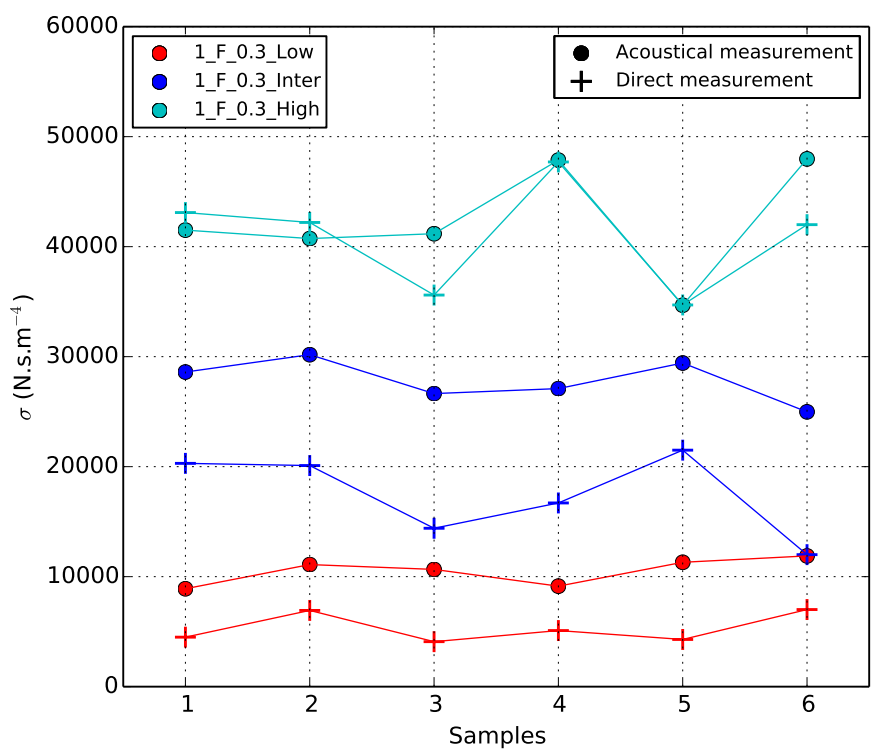

Figure 3: Comparison of acoustical and direct measurements of the resistivity for three mixes : 1_F_0.3_Low, 1_F_0.3_Inter and 1_F_0.3_High (respective average dry densities: 216, 265 and $309 \mathrm{~kg} \cdot \mathrm{m}^{-3}$ ) 
the acoustical parameters : acoustical parameters values for a given sample are slightly modified, but not in an extent that would modify the conclusions of the study.

\subsection{Acoustical properties}

Figure 4 shows typical results obtained for the sound absorption coefficient and sound transmission loss. These quantities are frequency-dependent. The following acoustical properties indicators were defined in order to facilitate the comparison between mixes: the frequency and level of the first peak for the sound absorption coefficient corresponding to the quarter-wave absorption, $f_{\lambda / 4}$ and $\alpha_{\lambda / 4}$, and the average level of the transmission loss on the range [250 Hz, $1000 \mathrm{~Hz}], T L_{[250,1000]}$.

Figure 5 shows the acoustical results (acoustical indicators and acoustical parameters) and the open porosity against the dry density. This representation shows a rather high variability of the results.

The same results are plotted against the hemp concentration (Figure 6), defined for each sample as the incorporated mass of hemp divided by the volume of this sample and given in $\mathrm{kg} \cdot \mathrm{m}^{-3}$. This choice of representation leads to a lower variability and highlights a direct link between these results and the hemp concentration. Thus, plotting against the dry density may be satisfactory and sufficient to obtain a raw estimation of the acoustical properties, but a detailed physical interpretation of the results requires plotting against the hemp concentration.

\subsubsection{Effect of the compaction level}

The variation of compaction within the explored range induces a density variation of $100 \mathrm{~kg} \cdot \mathrm{m}^{-3}$ in average. The effect of the compaction level is visible in all columns in Figures 5 and 6 . Concerning the acoustical parameters, Fig345 ure 5 shows that the porosities $\left(\phi_{\text {open }}\right.$ and $\left.\phi_{a c}\right)$ and the characteristic viscous length $(\Lambda)$ decrease with higher compaction, while the resistivity $(\sigma)$ increases. An increase of the tortuosity is also visible for dry densities up to $260 \mathrm{~kg} . \mathrm{m}^{-3}$, 

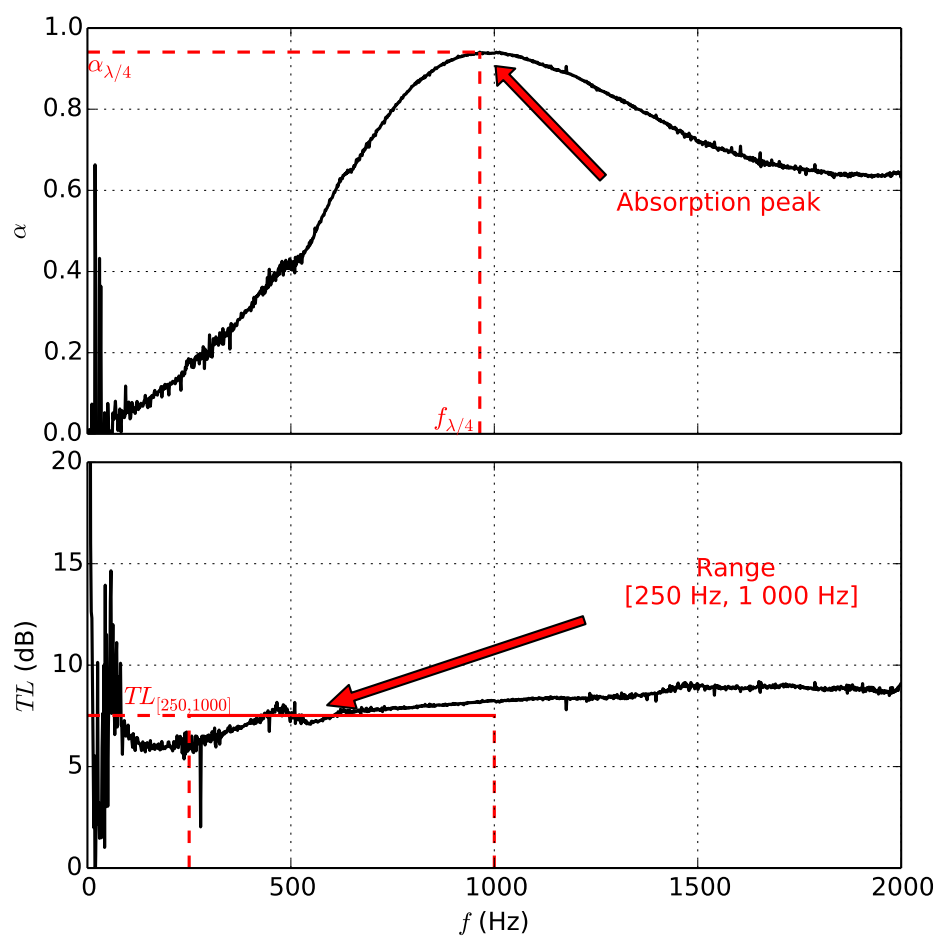

Figure 4: Example of results for the sound absorption coefficient $\alpha$ and sound transmission loss $T L$. 


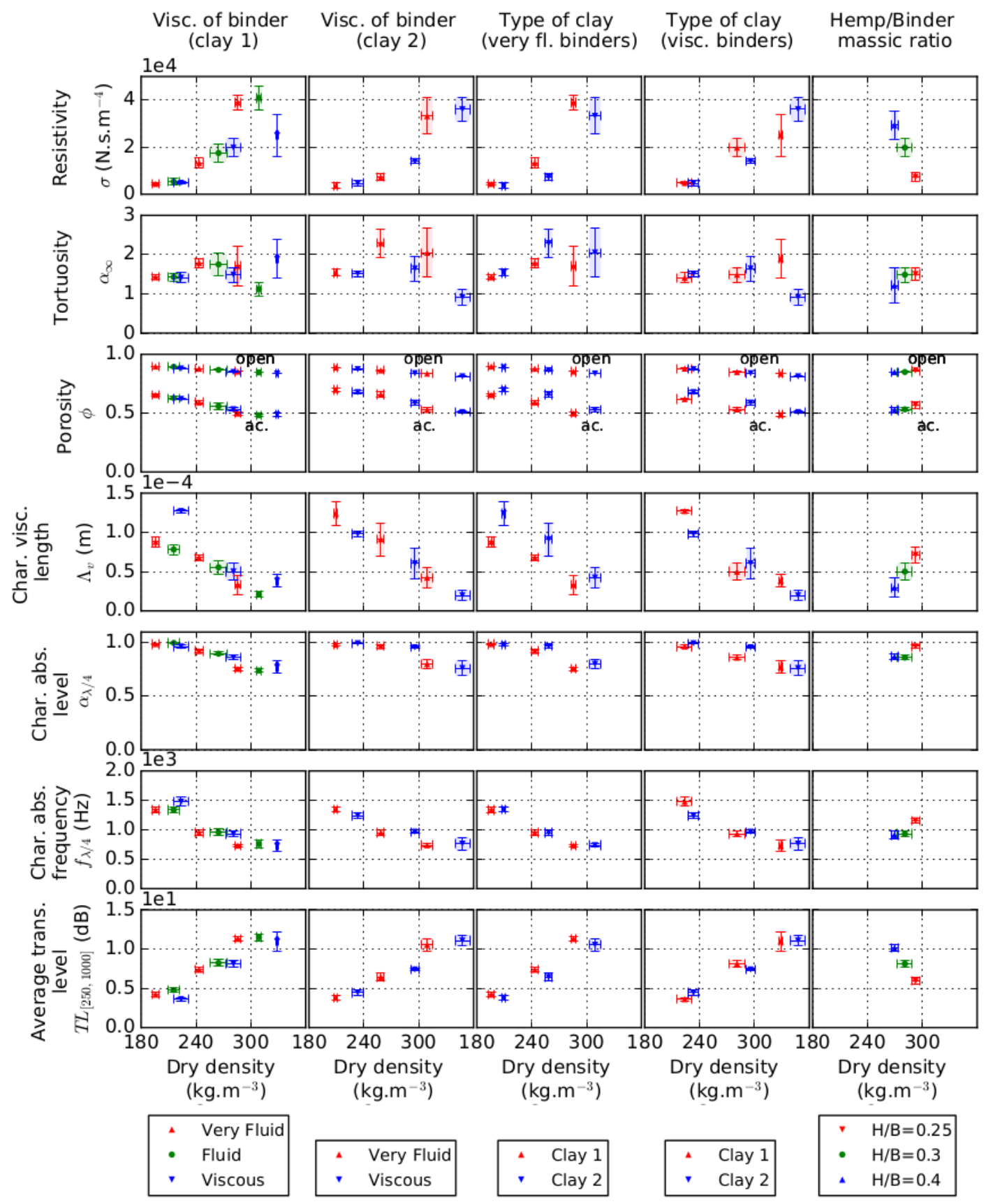

Figure 5: Mean properties indicators and acoustical parameters of hemp-clay samples plotted against the dry density. Each point represents an average value over 6 samples per mix, and the bars represent the standard deviation. 


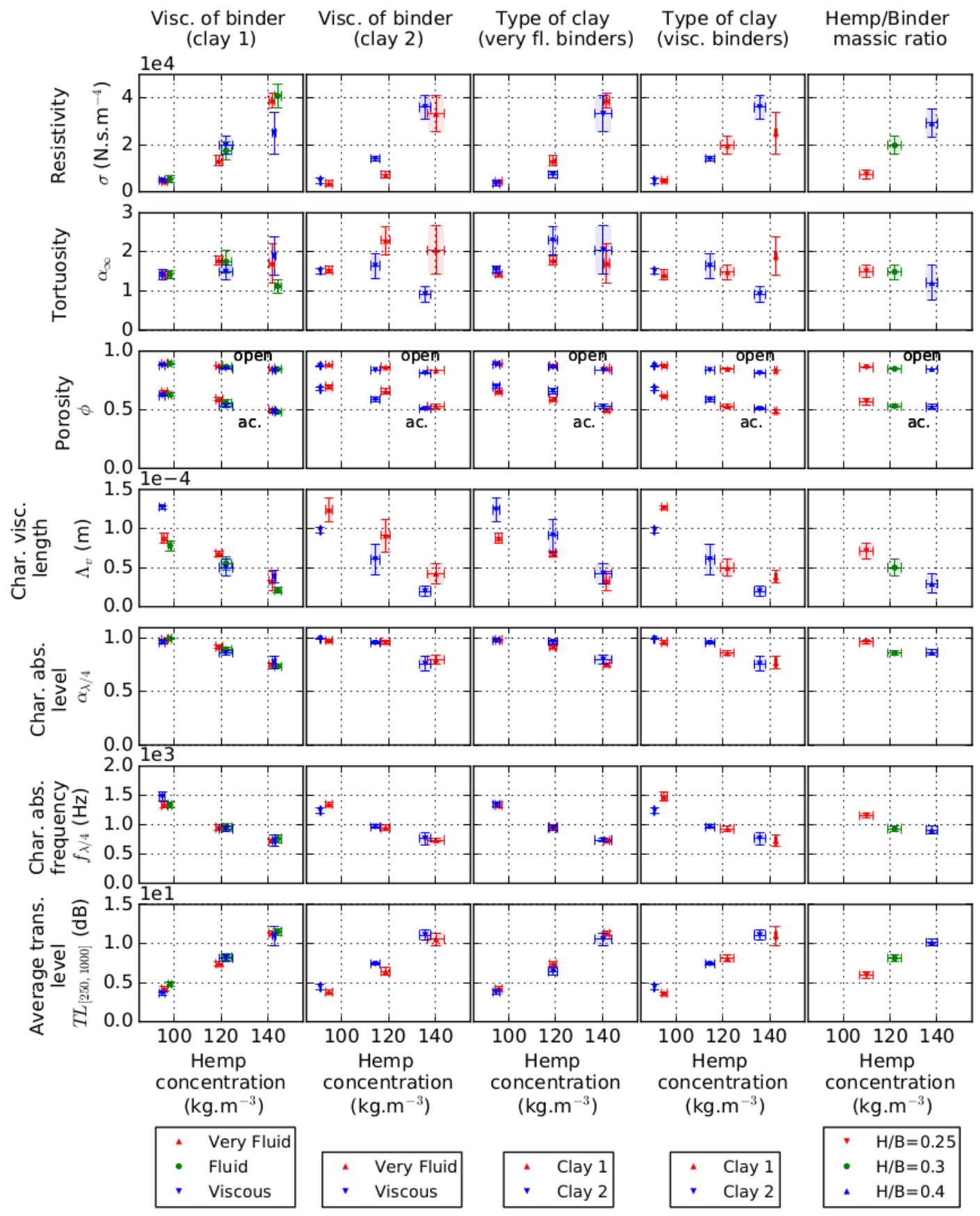

Figure 6: Mean properties indicators and acoustical parameters of hemp-clay samples plotted against the hemp concentration. Each point represents an average value over 6 samples per mix, and the bars represent the standard deviation. 
but is not clearly visible for higher densities, probably because characterization of this parameter becomes difficult for samples of large resistivity, such as high density hemp-clay mixes. These effects are not surprising and result from a tightening of the particles in the material [24]. Besides, these variations of the acoustical parameters have a direct effect on the acoustical properties, and $f_{\lambda / 4}$ and $\alpha_{\lambda / 4}$ decrease with higher compaction while $T L_{[250,1000]}$ increases, which is in line with the typical behaviour of the acoustical model.

\subsubsection{Effect of the binder viscosity}

The effect of the binder viscosity level is visible in columns 1 and 2 in Figures 5 and 6 . Unsurprisingly, the higher the viscosity, the higher the dry density. There is no visible effect of the viscosity of the binder on the level of the first absorption peak $\left(\alpha_{\lambda / 4}\right)$.

To compare the results with the different binder viscosities, it can be interesting not to focus on a particular compaction level, but to analyze the trends obtained for these viscosities when connecting dots corresponding to the three compaction levels.

Results obtained on clay 1 and 2 are similar. Given a dry density level, an increase of the fluidity of the binder seems to induce a reduction of the first peak frequency $\left(f_{\lambda / 4}\right)$, while both transmission loss $(T L)$ and resistivity $(\sigma)$ increase. However, given a hemp concentration, Figure 6 shows that there is no significative differences between the different viscosities. Therefore, our measurements indicate there is no direct effect of the binder viscosity on the acoustical properties. Different viscosities only lead to different densities because of different water contents.

\subsubsection{Effect of the type of clay}

The effect of the type of clay is visible in columns 3 and 4 in Figures 5 and 6. Clay 2 and clay 1 results are similar, with a density offset of about

$37520 \mathrm{~kg} \cdot \mathrm{m}^{-3}$. This shift is consistent since the water amount required to reach the same viscosity is slighlty higher for clay 1 than for clay 2 . Thus, clay type 
does not seem to have a significant effect on the acoustical performances (for the tested clays). This was not obvious since this binder was likely to affect the microstructure, similarly to the hemp concretes presented in [26].

\subsubsection{Effect of hemp/binder mass ratio}

The effect of the hemp/binder mass ratio is visible in column 5 in Figures 5 and 6. The proportion of hemp in mixes affects all indicators and parameters. Samples were manufactured with an identical wet mass, so the compaction level was adjusted to fit all the material into the mould (the higher the hemp content, the higher the compaction applied). Unsurprisingly, there is no direct correlation between the mass density and the resistivity $(\sigma)$. Indeed, a sample with $\mathrm{H} / \mathrm{B}=$ 0.4 can have a resistivity twice higher than a sample with $\mathrm{H} / \mathrm{B}=0.25$, due to different compaction levels.

\section{Modelling}

\subsection{Contribution of the different porosity levels}

Light earth is a porous material including a large part of air in its volume. Its open porosity $\left(\phi_{\text {open }}\right)$ is divided, similarly to hemp concretes [22, in three parts (for practical aspects, in this paper, close porosity is considered as a fraction of the frame volume):

- Interparticle porosity $\left(\phi_{\text {inter }}\right)$ characterizes the volume of open voids between particles, due to the imperfect layout of the parallelepiped shaped aggregates of hemp coated with clay.

- Intraparticle open porosity $\left(\phi_{\text {particle }}\right)$ is the open porosity within hemp particles, and corresponds to the vestige of the dense network of capillary vessels of the plant.

- Intrabinder open porosity $\left(\phi_{\text {clay }}\right)$ reflects the open porosity in clay itself, similarly to lime as discussed in introduction. 
In addition, we introduce the acoustical porosity $\left(\phi_{a c}\right)$, which is not linked to the material microstructure, but is the porosity level that contributes to the sound dissipation.

In motionless porous media, the material skeleton is rigid and does not participate to the sound dissipation (the validity of this hypothesis is discussed in the next section). Thus, acoustical dissipation is only affected by the open porosity $\left(\phi_{\text {open }}\right)$, as closed cells cannot be reached by the acoustical wave prop${ }_{410}$ agating in the air. However, not all the open porosity contributes to the sound dissipation, but only the pores that are large enough (typically greater than $10 \mu \mathrm{m})$. The reason is that the contrast of permeability between smaller pores (intrabinder and intraparticle pores) and greater pores (interparticle pores) is large, so that smaller pores are "invisible" to acoustic waves [23]. In hemp-lime ${ }_{415}$ concrete in the $200-500 \mathrm{~kg} \cdot \mathrm{m}^{-3}$ density range, the acoustical porosity is equal to the interparticle porosity $\left(\phi_{a c}=\phi_{\text {inter }}\right)[24,27$.

The acoustical porosity level $\left(\phi_{a c}\right)$ was estimated with the real part of the bulk modulus $\Re(K)$. At low frequency, its magnitude converges theoretically to $1 / \phi_{a c}$, which corresponds to an isothermal regime (thermal exchanges via conduction between pores and frame). At high frequency, it converges to $\gamma / \phi_{a c}$, which corresponds to an adiabatic regime (no exchanges between pores and frame) [21].

Figure 7 shows the measured bulk modulus for a sample with porosities $\phi_{\text {open }}=0.90$ and $\phi_{a c}=0.62$. This figure also shows the expected asymptotic

425 limits following two hypothesis : the acoustical behavior is due to the open porosity or the interparticle porosity. The experimental range of variation of the bulk modulus is clearly out of $\left[1 / \phi_{\text {open }}, \gamma / \phi_{\text {open }}\right]$. So, hemp-clay and hemplime behave in a similar way, with a major contribution of the interparticle porosity on the acoustical behavior $\left(\phi_{\text {acc }}=\phi_{\text {inter }}\right)$.

\subsection{Validity of the motionless skeleton hypothesis}

The aim of this section is to check the validity of the rigid frame hypothesis for hemp-clay. This hypothesis was used to quantify the acoustical porosity 


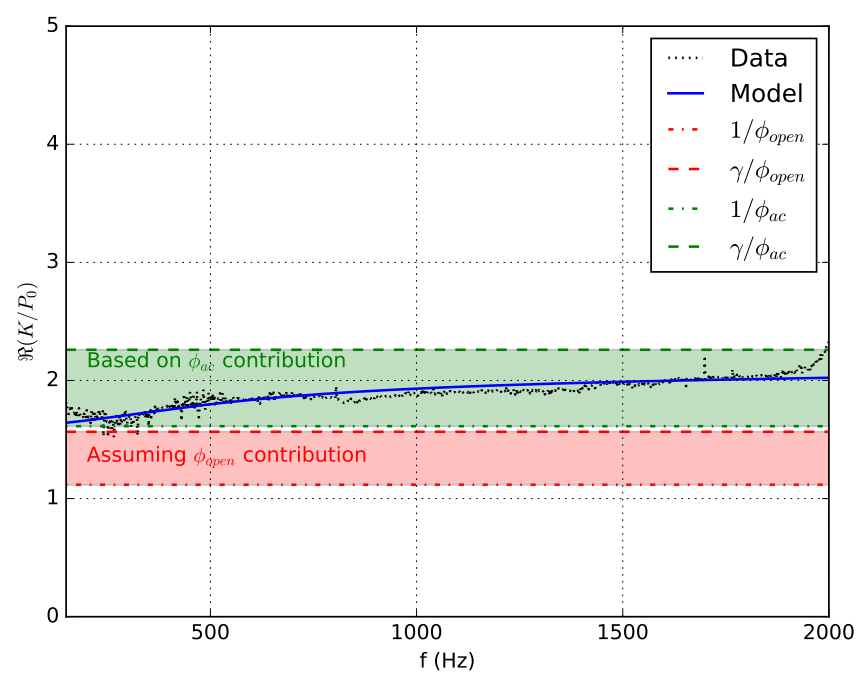

Figure 7: Comparison between the real part of normalized bulk modulus $\left(K / P_{0}\right)$ and the theoretical asymptotic limits $1 / \phi_{\text {open }}$ and $\gamma / \phi_{\text {open }}$, and effective asymptotic limits $1 / \phi_{a c}$ and $\gamma / \phi_{a c}$

from the Kundt sound absorption curves.

The fundamental theory of acoustical waves dissipation in porous and elastic 435 (reduced to poroelastic) materials has been introduced by the works of Biot [41, 42]. Biot described porous media as two-phases materials: one elastic solid phase saturated by a fluid phase (usually air). He showed that three kinds of waves can propagate in such material: a compressive wave and a shear wave in the solid phase, and a compressive wave in the fluid phase.

If the motionless skeleton hypothesis is valid, only visco-inertial and thermal effects have to be taken into account to describe the dissipation in the media above the decoupling frequency $f_{d}=\frac{\sigma \phi_{a c}^{2}}{2 \pi \mu}$ [34].

Experimentally, some of our measurements on hemp-clay (Figure 8) show a mechanical resonance on the sound absorption curves. This resonance corresponds to a mechanical 1D-compressive quarter-wave resonance of the solid phase (different from the quarter-wave peak observed on rigid frame sound absorption, which corresponds to a destructive interference between incident and 
reflected waves in the fluid phase). This is characteristic of soft materials [21, 22].

On the other hand, these sound absorption curves were modelled, assuming the motionless hypothesis was valid or not. The modellings use the alternative Biot's formulation detailed in [43, enabling a combination of visco-inertial and thermal effects with structural dissipation, assuming an elastic mechanical behaviour.

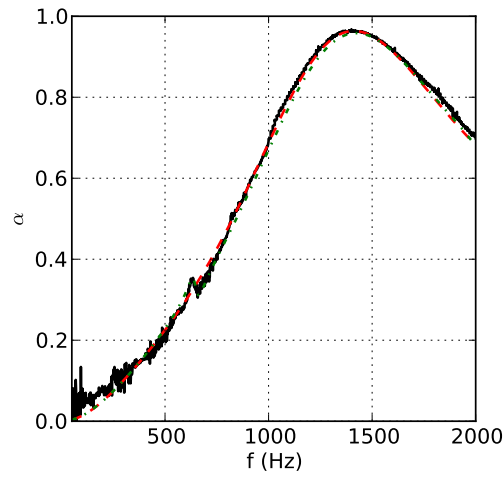

a) $219 \mathrm{~kg} \cdot \mathrm{m}^{-3}$

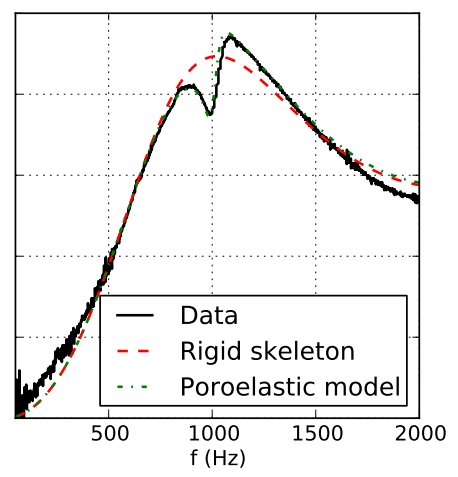

b) $290 \mathrm{~kg} \cdot \mathrm{m}^{-3}$

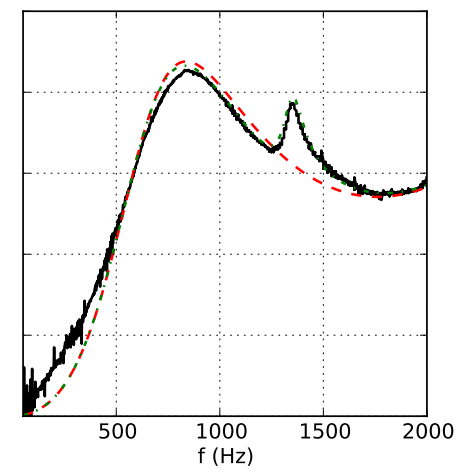

c) $330 \mathrm{~kg} \cdot \mathrm{m}^{-3}$

Figure 8: Measured absorption data for three hemp-clay samples (see detailed characteristics in Table 9, compared to rigid frame and poroelastic modellings.

\begin{tabular}{|c|c|c|c|c|c|c|c|c|c|}
\hline Samples & $\begin{array}{c}\mathrm{e} \\
(\mathrm{m})\end{array}$ & $\phi_{a c}$ & $\begin{array}{c}\sigma \\
\left(\text { N.s.m }{ }^{-4}\right)\end{array}$ & $\alpha_{\infty}$ & $\begin{array}{c}\Lambda \\
(\mu \mathrm{m})\end{array}$ & $\begin{array}{c}\mu \\
\left(\mathrm{kg} \cdot \mathrm{m}^{-3}\right) \\
\end{array}$ & $\begin{array}{c}\mathrm{E} \\
(\mathrm{MPa})\end{array}$ & $\nu$ & $\xi$ \\
\hline $1_{-} V_{-} 0.3_{-}$Low $_{-} 5$ & 0.039 & 0.62 & 6500 & 1.90 & 204 & 219 & 2.2 & 0.05 & 0.05 \\
\hline${ }^{1}{ }_{-}{ }_{-} 0.3_{-}$Inter_ 1 & 0.039 & 0.53 & 34400 & 2.60 & 107 & 290 & 7.0 & 0.05 & 0.05 \\
\hline 1_V_0.3_High_6 & 0.042 & 0.48 & 25000 & 1.90 & 54 & 330 & 16.5 & 0.05 & 0.08 \\
\hline
\end{tabular}

Table 9: Poroelastic parameters of the samples.

The acoustical properties of hemp-clay can be directly computed from interparticle acoustical properties, characterized by the acoustical porosity $\phi_{a c}$ :

$$
\begin{array}{r}
\rho=\rho_{\text {inter }} \\
K=K_{\text {inter }}
\end{array}
$$

Besides the four parameters of the model that account for acoustical dissipa- 
tion, four parameters account for the mechanical dissipation in the samples: the dry density $\mu$, the Young's modulus $E$, the Poisson's ratio $\nu$ and the structural damping $\xi$. $E$ has been deduced from sound absorption data, while $\nu$ and $\xi$ were set to 0.05 , accordingly to the literature on similar materials [22, 44].

The agreement between the poroelastic modelling and the data is excellent, even when the structural resonance is pronounced. Data and poroelastic model agree for sound absorption with an error lower than $5 \%$. The agreement between the rigid frame modelling and the data is also excellent outside the resonance frequency band (error lower than 5\%), but this simplified modelling cannot 465 reproduce the mechanical resonance peak. The difference is limited for light samples (Figure 8 a)) but can be significant for higher densities (see Figure 8 b) and c)). This leads to differences in amplitude at the resonance frequency between experimental and modelling up to $20 \%$. However, this comparison shows the simplified modelling is a satisfactory quantitative approach, even if it neglects the resonance peak: the motionless porous behaviour of hemp-clay is justified.

Eventually, this analysis shows the modelling approach proposed for hemplime is also correct for hemp-clay. The physical phenomenons accounting for the sound absorption in these materials are similar. Furthermore, it can be

475 assumed that this modelling also holds for higher densities, because the double porosity behaviour would behave in a similar way. This result is useful since heavier samples are particularly difficult to characterize experimentally, due to their high resistivity.

\section{Discussion}

\subsection{Acoustical performances of hemp-clay}

Hemp-clay can be produced with a large range of manufacturing parameters (density, ratio between constituents, nature of the constituents, building technique...). The present study was focused on the range $200-360 \mathrm{~kg} \cdot \mathrm{m}^{-3}$. But, in a preliminary study, hemp-clay samples with densities ranging from 229 
to $821 \mathrm{~kg} \cdot \mathrm{m}^{-3}$ were analysed in the Kundt tube. An overview of the available spectrum of performances is presented Figure 9. It shows hemp-clay can result in a large assortment of possible acoustical performances, concerning sound absorption $(\alpha)$ as well as transmission loss $(T L)$.

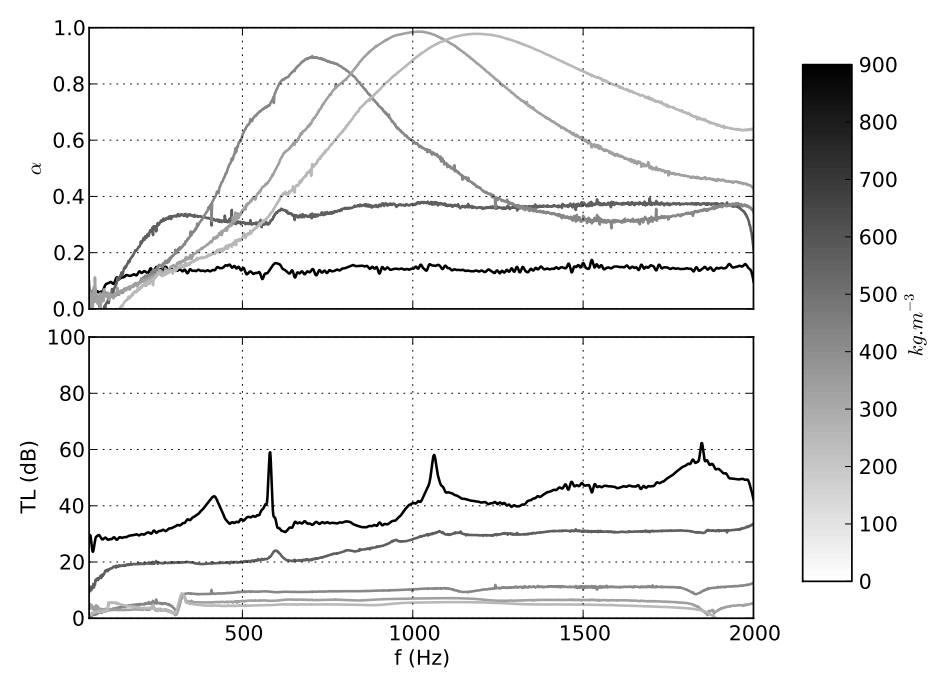

Figure 9: Range of performances achieved with hemp-clay mixtures. Formulations having densities of respectively 229, 306, 386, 517 and $821 \mathrm{~kg} \cdot \mathrm{m}^{-3}$ (lines are darker for heavier samples).

\subsection{Hemp-clay versus hemp-lime}

The modelled sound absorption and transmission loss of three classes of densities of hemp-clay are compared in Figure 10 to hemp-lime samples of similar densities (modelling was performed using the rigid frame approach discussed in Section 3.2. Their averaged densities and acoustical parameters are given Table 10.

The shapes of hemp-clay and hemp-lime sound absorption at a given density are similar. A density increase affects the same way both materials: absorption peak moves to lower frequencies with a lower amplitude. Interestingly, these similar shapes are obtained while hemp-clay samples have a larger resistivity 


\begin{tabular}{lccccc}
\hline Material & $\begin{array}{c}\text { Dry density } \\
\left(\mathrm{kg} . \mathrm{m}^{-3}\right)\end{array}$ & $\phi_{a c}$ & $\begin{array}{c}\sigma \\
\left(\mathrm{N}^{-s . m^{-4}}\right)\end{array}$ & $\alpha_{\infty}$ & $\begin{array}{c}\Lambda \\
(\mu \mathrm{m})\end{array}$ \\
\hline \multirow{4}{*}{ Hemp-clay } & 195 & 0.61 & 13000 & 1.9 & 150 \\
& 340 & 0.50 & 30000 & 1.1 & 22 \\
& 461 & 0.47 & 185000 & 1.2 & 5.5 \\
\hline \multirow{4}{*}{ Hemp-lime } & 180 & 0.70 & 4000 & 2.4 & 236 \\
& 339 & 0.55 & 9400 & 3.8 & 94 \\
\hline
\end{tabular}

Table 10: Comparison of characteristics of hemp-clay and hemp-lime samples (data concerning hemp-lime samples are taken from [22]) for $5 \mathrm{~cm}$ thick samples.

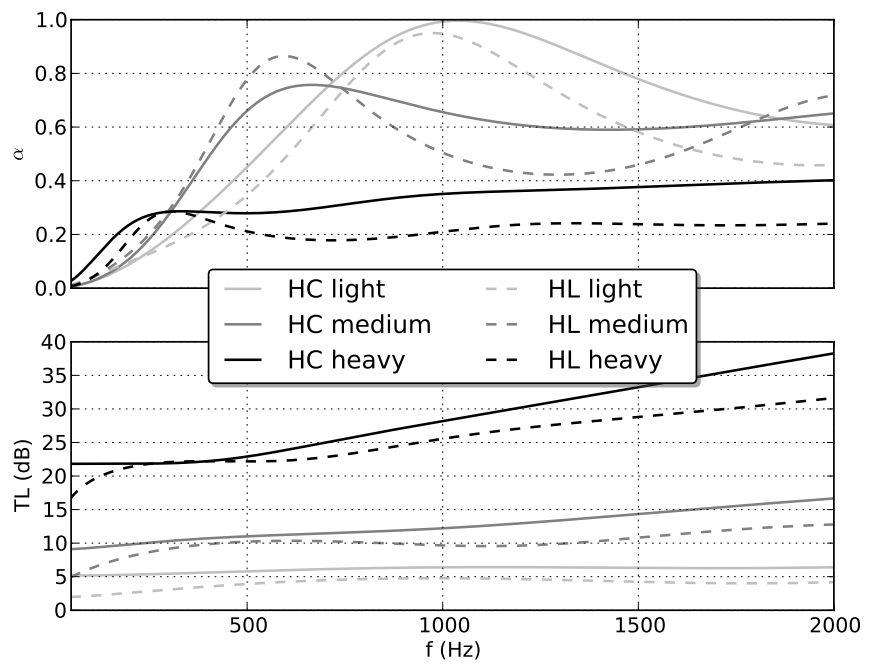

Figure 10: Comparison of hemp-clay (HC) and hemp-lime (HL) modelled sound absorption and transmission loss for three classes of density (Lines are darker for heavier samples). 
$\sigma$ (up to a factor of 10), smaller porosity $\phi_{a c}$ and characteristic pores sizes $\alpha_{\infty}$ (Table 10). Another difference is that the absorption peak for hemp-lime is narrower. This might be due to the greater tortuosity $\alpha_{\infty}$ in hemp-lime (Table 10) than in hemp-clay, the difference being above uncertainty level. This difference might be related to the lower density of the binder in hemp-lime mixes (1 000 to $1300 \mathrm{~kg} \cdot \mathrm{m}^{-3}$ in [22]) compared to the binder density in hemp-clay 505 (1 600 to $1800 \mathrm{~kg} \cdot \mathrm{m}^{-3}$ according to the data presented in Table 2). A lower density could result in stronger microstructure clogging effects.

Concerning transmission loss, the larger resistivity of hemp-clay results in a greater TL, with a difference of $3 \mathrm{~dB}$ on average in the considered frequency range.

Further investigations of the differences between hemp-clay and hemp-lime have been carried out, comparing three characteristics (Figure 11):

- the sound absorption of the first peak $\alpha_{\lambda / 4}$,

- the frequency of the first peak $f_{\lambda / 4}$,

- the static airflow resistivity $\sigma$.

To eliminate the possible frequency shift and amplitude modulation of absorption due to the mechanical resonance peak (Figure 8), $\alpha_{\lambda / 4}$ and $f\left(\alpha_{\lambda / 4}\right)$ have been evaluated on the rigid skeleton modelling of the samples.

Samples were $4 \mathrm{~cm}$ thick for hemp-clay and $5 \mathrm{~cm}$ for hemp-lime. The peak frequency position $f_{\lambda / 4}$, which corresponds to quarter-wave frequency, is related to the thickness of the materials. Thus, the frequency of hemp-clay samples have been corrected to correspond to $5 \mathrm{~cm}$ samples using the following expression: $f_{\lambda / 4}=\frac{e}{0.05} f_{\lambda / 4, \text { raw }}$.

The maximal sound absorption $\alpha_{\lambda / 4}$ as well as the frequency of this maximum $f_{\lambda / 4}$ are similar for hemp-lime and hemp-clay, while in agreement with the 525 analysis made above with Figure 10 and Table 10 . Figure 11 allows to define the density range for the change of sound absorption behaviour: 


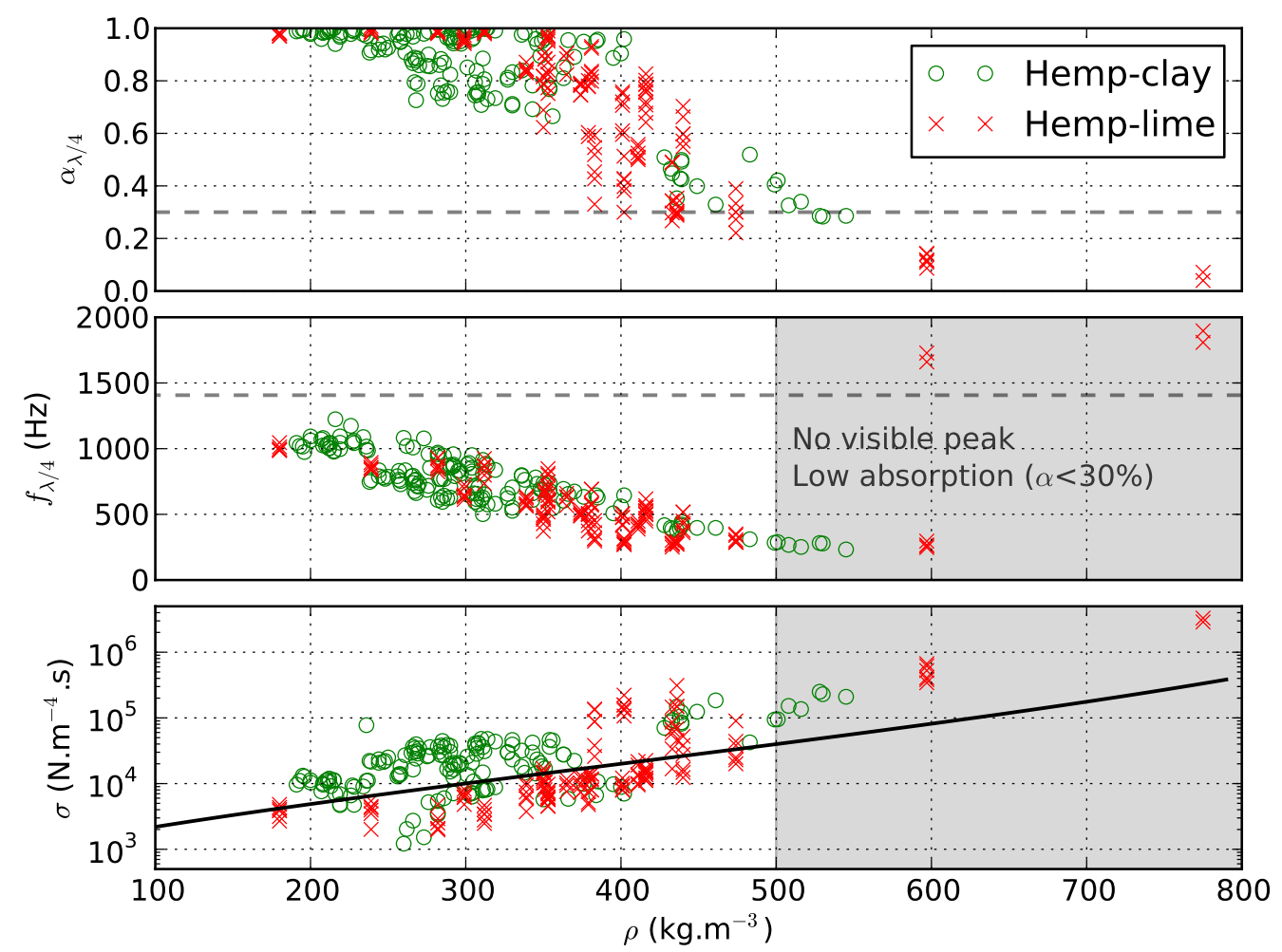

Figure 11: Acoustical characteristics of hemp-lime and hemp-clay as a function of density. 
- below $375 \mathrm{~kg} . \mathrm{m}^{-3}$, a highly absorbent $(0.6$ - 1) first peak appears between 500 and $1200 \mathrm{~Hz}$,

- between 375 to $500 \mathrm{~kg} \cdot \mathrm{m}^{-3}$, the first peak amplitude is highly scattered between 0.3 and 0.8 , which shows a strong dependence of the acoustical performance on the manufacturing process,

- above $500 \mathrm{~kg} \cdot \mathrm{m}^{-3}$, the sound absorption curve is a plateau, with a transmission loss $(T L)$ increasing with density (Figure 9). The same figure shows a level of $30 \mathrm{~dB}$ is reached at $821 \mathrm{~kg} \cdot \mathrm{m}^{-3}$ for a $4 \mathrm{~cm}$ thick sample (considering a rigid frame). Applied to building works, this result corresponds to hemp-clay applied with a trowel, with a density from 800 to $900 \mathrm{~kg} \cdot \mathrm{m}^{-3}$. This is the typical mix used to apply a $6 \mathrm{~cm}$ coating on an existing wall, to bring not only a "thermal correction", but also a significant sound transmission reduction.

540

Besides, Figure 11 confirms on a large experimental database that resistivity values are greater for hemp-clay samples, especially for lower densities $(\mu<$ $400 \mathrm{~kg} \cdot \mathrm{m}^{-3}$ ). The origin of this effect is not known yet, but a better coating of the particle by clay binders or a bad setting of lime or powdering effect in hemp-lime could be partly at the origin of such effects.

545

To analyse this evolution of $\sigma$, the resitivity values have been compared to a self-consistent modelling approach (black solid line in Figure 11) with the following assumptions:

- the granular model presented in [45] and successfully applied to hemp shiv in [24] has been used,

550

- the radius $R$ of the aggregates has been set to $250 \mu \mathrm{m}$, a characteristic value for shiv [24] and this same radius have been considered for all mixes,

- the evolution of porosity $\phi_{a c}$ has been approximated as a function of density, using Equation 11 and:

$$
\text { - hemp concentration } C_{\text {hemp }}=110 \mathrm{~kg} \cdot \mathrm{m}^{-3} \text {, }
$$


- hemp apparent density $\mu_{\text {particles }}=500 \mathrm{~kg} \cdot \mathrm{m}^{-3}[24$,

- binder apparent density $\mu_{\text {binder }}=1400 \mathrm{~kg} \cdot \mathrm{m}^{-3}$, intermediate between clay (see Table2) and lime [22] apparent density.

$$
\begin{array}{r}
\phi_{a c}=1.0-\frac{C_{\text {hemp }}}{\mu_{\text {particles }}}-\frac{\mu-C_{\text {hemp }}}{\mu_{\text {binder }}} \\
\sigma=\frac{A \eta\left(1-\phi_{a c}\right)^{2}}{\left(\frac{4}{3} \pi\right)^{2 / 3} R^{2} \phi_{a c}^{3}} \\
A=\frac{25.4 \phi_{a c}^{3}}{\left(1-\phi_{a c}\right)^{2 / 3}\left(1-\left(1-\phi_{a c}\right)^{1 / 3}\right)\left(1-\left(1-\phi_{a c}\right)^{2 / 3}\right)^{2}}
\end{array}
$$

On this basis, it appears that the model follows the general trend described by the experimental data up to dry densities of $500 \mathrm{~kg} \cdot \mathrm{m}^{-3}$, and that the granular approach is consistent for this range. For higher densities, this "perfect" granular media approach is no longer valid, probably because of a difference between the acoustical porosity and the porosity involved in air flow.

\section{Conclusion}

This experimental and modelling study provides a detailed knowledge of the acoustic performances of hemp-lime and hemp-clay at the material scale.

In hemp-clay concrete, our experimental results show the concentration of hemp in a mix has a first order effect on the acoustical performance, while binder fluidity and clay type have no effect. More globally, our paper demonstrates that hemp-clay and hemp-lime mixes acoustically behave in a similar way. Their densities are located in the same range, their absorption peak position and amplitude are similar due to a major contribution of the interparticle pores. To summarize, three different acoustical behaviors can be distinguished :

- below $375 \mathrm{~kg} \cdot \mathrm{m}^{-3}$ : a highly absorbent (0.6 - 1) first peak appears between 500 and $1200 \mathrm{~Hz}$,

- between 375 to $500 \mathrm{~kg} \cdot \mathrm{m}^{-3}$ : the first peak amplitude is highly scattered between 0.8 and 0.3 , which shows a strong dependence of the performance on the manufacturing process, 
- above $500 \mathrm{~kg} \cdot \mathrm{m}^{-3}$ : the sound absorption curve is a plateau, with transmission loss $(T L)$ increasing with density.

s80 It should be underlined that a scientific accurate analysis of biobased concrete acoustical properties should be done using their hemp to binder ratio rather than their density. Nonetheless, using the density is sufficient to estimate the acoustical behavior to design a building, and it is a more spread concept among craftmen and building designer. Thus, the classification we proposed in terms of performances of hemp-based concrete.

However, we found small accoustical differences between lime and clay binder concrete :

- the width of the absorption peak is lower for hemp-lime likely due to a higher tortuosity,

- the air resistivity for a given density is higher for hemp-clay than for hemp-lime (likely because clay binder frame density is greater than lime one).

The impact of these differences on the acoustical behavior is small enough to be neglected in the acoustical design of a building.

The experimental sound absorption and transmission data were finally modelled with a physical-based four-parameters approach with a close agreement, which highlights the good level of understanding of the physical phenomena responsible for the acoustical behavior of hemp concrete.

600

Some questions remains at the material scale, such as the influence of the building technique (casted, sprayed...) on the potential anisotropic behavior. In addition, this study can be extended to biobased concrete using other granulates (sunflower, rape straw...), which can be straightforward since the acoustical behavior might also be mainly due to interparticle pores. However, we believe 605 that the most important future work is to caracterize the behavior at the wall scale, taking into account different construction techniques. 


\section{Acknowledgments}

Authors are grateful to Annick Lalloret and Erwan Hamard for clay analyses, and Benjamin Hellouin de Menibus for proof-checking.

This study is a part of the ECO-TERRA project (Development of light earth construction materials for efficient green buildings), with the support of the ADEME, Normandy Region, DIRECCTE Normandie, La Fondation de France, Britanny Region, the French Ministry of Education and Research, the Fondation d'entreprise Legallais.

\section{References}

[1] M. K. Dixit, J. L. Fernàndez-Solìs, S. Lavy, C. H. Culp, Identification of parameters for embodied energy measurement: A literature review, Energy and Buildings 42 (8) (2010) 1238-1247.

[2] S. Mandley, R. Harmsen, E. Worrell, Identifying the potential for resource and embodied energy savings within the UK building sector, Energy and Buildings 86 (2015) 841-851.

[3] L. Zampori, G. Dotelli, V. Vernelli, Life cycle assessment of hemp cultivation and use of hemp-based thermal insulator materials in buildings, Environmental Science \& Technology 47(13) (2013) 7413-7420.

625 [4] NF P75-101 : Isolants thermiques destinés au bâtiment - Définition (Thermal insulation materials for buildings - Definition) (1983).

[5] F. Volhard, Construire en terre allégée (Building in light earth), Actes Sud, 2016.

[6] N. Oudhof, M. Labat, C. Magniont, P. Nicot, Measurement of the hygrothermal properties of straw-clay mixtures, in: ICBBM 2015, ClermontFerrand, First International Conference on Bio-based Building Materials, Clermont Ferrand, France, 2015, pp. 474-479. 
[7] E. Kuersten, Coir - traditionally used fibre for new construction applications, in: ICBBM, Clermont-Ferrand, First International Conference on Bio-based Building Materials, Clermont Ferrand, France, 2015, pp. 18 22 .

[8] E. Samin, Production de matériaux d'isolation thermique à base de Typha. Session comprendre la matière (Production of thermal insulation materials based on typha. Session understand the material), in: PROJET PNEEB / TYPHA, Diamniadio, 2015, p. 10.

[9] R. Busbridge, Hemp-Clay: an initial investigation into the thermal, structural and environmental credentials of monolithic clay and hemp walls, Master of sciences, Centre for Alternative Technology, UK and School of Computing and Technology University of East London, UK (2009).

[10] Y. Brouard, N. Belayachi, D. Hoxha, S. Méo, A. Wajih, Hygrothermal behavior of clay - sunflower (helianthus annuus) and rape straw (brassica napus) plaster bio-composites for building insulation, in: International Conference - Towards a Sustainable Urban Environment (EBUILT-2016), Iasi, Romania), 2016.

[11] C. Palmar, A comparison of moisture content versus thermal conductivity of low impact construction materials: straw and hemp with binders, MSc Architecture, Graduate School of the Environment Centre for Alternative Technology (2010).

[12] F. Collet, Caractérisation hydrique et thermique de matériaux de génie civil à faibles impacts environnementaux (Hydric and thermal characterization of civil engineering materials having a low environmental impact), Ph.D. thesis, INSA Rennes (2004).

[13] V. Cerezo, Propriétés mécaniques, thermiques et acoustiques d'un matériau à base de particules végétales: approche expérimentale et modélisation théorique (Mechanical, thermal and acoustical properties of a material 
based on vegetal particles: experimental approach and theoretical modelling), Ph.D. thesis, INSA Lyon (2005).

[14] T. Colinart, P. Glouannec, T. Pierre, P. Chauvelon, A. Magueresse, Experimental Study on the Hygrothermal Behavior of a Coated Sprayed Hemp Concrete Wall, Buildings 3 (2013) 79-99.

[15] ISO, Acoustics - Measurement of sound insulation in buildings and of building elements - Part 5: Field measurements of airborne sound insulation of facade elements and facades (1998).

[16] ISO, Acoustics - Measurement of sound absorption in a reverberation room (2003).

[17] ISO, Acoustics - Measurement of sound insulation in buildings and of building elements - Part 3: Laboratory measurements of airborne sound insulation of building elements (1995).

[18] ISO, Acoustics - Determination of sound absorption coefficient and impedance in impedance tubes - Part 2: Transfer-function method (2003).

[19] T. Iwase, Y. Izumi, R. Kawabata, A new measuring method for sound propagation constant by using sound tube without any air spaces back of a test material, Internoise 98, Christchurch, New Zealand (1998) 4.

[20] B.-H. Song, J.-S. Bolton, A transfer-matrix approach for estimating the characteristic impedance and wave numbers of limp and rigid porous materials, Journal of the Acoustical Society of America 107(3) (2000) 1131-1152.

[21] J.-F. Allard, N. Atalla, Propagation of Sound in Porous Media: Modelling Sound Absorbing Materials, Second Edition, Wiley, 2009.

[22] P. Glé, Acoustique des matériaux du bâtiment à base de fibres et particules végétales - Outils de caractérisation, modélisation et optimisation (Acoustics of building materials based on vegetal fibers and particles - Tools of 
characterization, modelling and optimization), Ph.D. thesis, Ecole doctorale MEGA - ENTPE - Université de Lyon (2013).

[23] X. Olny, C. Boutin, Acoustic wave propagation in double porosity media, Journal of the Acoustical Society of America 114 (1) (2003) 73-89.

[24] P. Glé, E. Gourdon, L. Arnaud, Modelling of the acoustical properties of hemp particles, Construction and Building Materials 37 (2012) 801-811.

[25] P.-A. Chabriac, E. Gourdon, P. Glé, A. Fabbri, H. Lenormand, Agricultural by-products for building insulation: Acoustical characterization and modelling to predict microstructural parameters, Construction and Building Materials 112 (2015) 158-167.

[26] P. Glé, E. Gourdon, L. Arnaud, Acoustical properties of materials made of vegetable particles with several scales of porosity, Applied Acoustics 72 (2011) 249-259.

[27] P. Glé, K. Horoshenkov, E. Gourdon, L. Arnaud, A. Khan, The effect of particle shape and size distribution on the acoustical properties of mixtures of hemp particles, Journal of the Acoustical Society of America 134 (6) (2013) 4698-4709.

[28] M. Arandigoyen, J.-L. P. Bernal, M.-A. B. Lopez, J.-I. Alvarez, Limepastes with different kneading water: Pore structure and capillary porosity, Applied Surface Science 252 (2005) 1449-1459.

[29] A. Chiappone, S. Marello, C. Scavia, M. Setti, Clay mineral characterization through the methylene blue test: comparison with experimental techniques and applications of the method, Revue canadienne de geotechnique 41 (6) (2004) 1168-1178.

[30] S. Amziane, F. Collet (Eds.), Bio-aggregates Based Building Materials, Vol. 23 of RILEM State-of-the-Art Reports, Springer Netherlands, Dordrecht, 2017. 
[31] Y. Miki, Acoustical properties of porous materials. Modifications of DelanyBazley models., Journal of the Acoustical Society of Japan (E) 11 (1) (1990) $19-24$.

[32] K. Attenborough, On the acoustic slow wave in air-filled granular media, Journal of the Acoustical Society of America 81 (1) (1987) 93-102.

[33] D.-L. Johnson, J. Koplik, R. Dashen, Theory of dynamic permeability and tortuosity in fluid-saturated porous media, Fluid Mechanics 176 (1987) 379-402.

[34] C. Zwikker, C.-W. Kosten, Sound absorbing materials, Elsevier, New-York (1949) 174.

[35] K.-V. Horoshenkov, K. Attenborough, S.-N. Chandler-Wilde, Padé approximants for the acoustical properties of rigid frame porous media with pore size distributions, Journal of the Acoustical Society of America 104 (3) (2007) 1198-1209.

[36] D. Lafarge, P. Lemarinier, J.-F. Allard, V. Tarnow, Dynamic compressibility of air in porous structures at audible frequencies, Journal of the Acoustical Society of America 102 (4) (1997) 1995-2006.

[37] X. Olny, R. Panneton, J. Tran-Van, An indirect acoustical method for determining intrinsic parameters of porous materials, Proceedings of the $2^{\text {nd }}$ Biot conference, Grenoble (2002) 6 .

[38] R. Panneton, X. Olny, Acoustical determination of the parameters governing viscous dissipation in porous media, Journal of the Acoustical Society of America 119 (4) (2006) 2027-2040.

[39] ISO, Acoustics - Materials for acoustical applications - Determination of airflow resistance (1991).

[40] P. Leclaire, O. Umnova, K.-V. Horoshenkov, L. Maillet, Porosity measurement by comparison of air volumes, Review of scientific instruments 74 (3) (2003) 1366-1370. 
[41] M.-A. Biot, Theory of propagation of elastic waves in a fluid-saturated porous solid. I Low-frequency range, Journal of the Acoustical Society of America 28 (1956) 168-178.

[42] M.-A. Biot, Theory of propagation of elastic waves in a fluid-saturated porous solid. II High-frequency range, Journal of the Acoustical Society of America 28 (1956) 179-191.

[43] F.-X. Bécot, L. Jaouen, An alternative Biot's formulation for dissipative porous media with skeleton deformation, Journal of the Acoustical Society of America 134 (6) (2013) 4801-4807.

[44] H. Lenormand, P. Glé, N. Leblanc, Investigation of the acoustical and thermal properties of sunflower particleboards, Acta Acustica united with Acustica 103 (2017) 149-157.

[45] J. Prieur du Plessis, S. Woudberg, Pore-scale derivation of the ergun equation to enhance its adaptability and generalization, Chemical Engineering Science 63 (9) (2008) $2576-2586$. 